\title{
INTEGRASI PEMIKIRAN IMAM AL-GHAZALI \& IVAN PAVLOV DALAM MEMBENTUK PERILAKU PESERTA DIDIK
}

\section{Umaruddin Nasution \& Casmini}

Universitas Islam Negeri Sunan Kalijaga Yogyakarta

Abstrak:This study aims to analyze the relationship between the thoughs of al-Ghazali and Ivan Pavlov in establishing educational behaviours. In this study took two figures: The first Imam Al-Ghazali, which is one of the Sufi figures using the riyadhoh concept and dubbed it the hujjatul Islam and secondly Ivan Patrovich Pavlov which is one of the behavioristik learning theory using the classical conditioning concept dubbed the father behavioristic theory. This type of research is are search library based on the books of the two figures. The approach philosophical-historical and content analysis are a reference in providing an explanation of the results of the data found. The results of this study indicate that by taking the road to habituation will be able to provide a change in one is behaviour. Refraction is done in three stages, namely takhalli (unconditioning stimulus), tahalli (conditioning stimulus), and tajalli (conditioning response) in order to reflect the good behavior become a habitual hai'ah in self learners.

Keywords: Habituation, riyadhoh, classical conditioning, behaviour.

Abstrak: Penelitian ini bertujuan untuk menganalisis relasi antara pemikiran Imam AlGhazali dan Ivan Pavlov dalam membentuk perilaku peserta didik dengan jalan pembiasaan. Dalam penelitian ini mengambil dua tokoh: Pertama, Imam AlGhazali yang merupakan salah satu tokoh sufistik dengan menggunakan konsep riyadhoh dan dijuluki sebagai hujjatul Islam, Kedua, Ivan Patrovich Pavlov yang merupakan salah satu tokoh teori belajar behavioristik dengan menggunakan konsep classical conditioning dan dijuluki sebagai bapak teori behavioristik. Penelitian yang digunakan adalah library research dengan berpedoman pada bukubuku dari kedua tokoh tersebut. Pendekatan filosofis-historis dan content analysis menjadi acuan dalam memberikan penjelasan hasil data yang ditemukan. Hasil dari penelitian ini menunjukkan bahwa dengan menempuh jalan pembiasaan akan dapat memberikan perubahan pada tingkah laku seseorang. Pembiasaan dilakukan melalui tiga tahapan yaitu takhalli (unconditioning stimulus), tahalli (conditioning stimulus), dan tajalli (conditioning respons) untuk dapat merefleksikan perilaku yang baik menjadi sebuah habits yang hai'ah dalam diri peserta didik.

Kata kunci: Pembiasaan, riyadhoh, classical conditioning, perilaku

\section{A. PENDAHULUAN}

Perilaku merupakan cerminan dari representasi hati yang ada pada diri manusia. Representasi tersebut diidentikkan dengan perbuatan atau perlakuan manusia baik dalam keadaan sadar (concious state) maupun dalam keadaan tidak sadar (unconscious) 
(Ahmad, 2011; Custers \& Aarts, 2010). Ibnu Maskawaih mengatakan perilaku merupakan keadaan jiwa (nafs) seseorang yang mendorong dirinya untuk melakukan perbuatan tanpa memerlukan atau melalui pertimbangan dan pemikiran untuk melakukannya (Zahruddin dan Sinaga, 2004). Perbuatan dan perlakuan yang ditimbulkan tersebut berguna untuk merepresentasikan aktivitas-aktivitas dalam kehidupan sehari-hari. Oleh sebab itu, setiap manusia harus menjaga keindahan perilaku, dan tata aturan tingkah laku yang mencakup segala aspek dan elemen dalam kehidupannya (Zulfahmi dan Hasmah, 2014).

Aktivitas-aktivitas dalam kehidupan manusia sehari-hari merepresentasikan dua dimensi tingkah laku dan perbuatan, yaitu pertama, perilaku atau perbuatan yang merepresentasikan personality baik akan mencerminkan manusia yang berperilaku baik (khuluqal-hasan) dan akan memiliki sifat mulia yang membawa kebahagiaan serta kesempurnaan. Kedua, perilaku yang merepresentasikan personality buruk akan mencerminkan manusia yang berakhlak buruk (khuluqal-sayyi), dan akan memiliki sifat buruk yang membawa kesengsaraan dan penyiksaan hidup (Al-Ghazali, 2014). Dalam tatanan ajaran agama Islam mengatur setiap aspek kehidupan manusia, baik hubungan yang secara vertikal antara hamba dengan Tuhan-nya (hablum minallah), maupun hubungan yang secara horizontal antara manusia dengan manusia lainnya (hablum minannas). Sebagaimana dijelaskan dalam firman Allah SWT yang artinya:

"Sembahlah Allah dan janganlah kamu mempersekutukan-Nya dengan sesuatupun. Dan berbuat baiklah kepada kedua ibu-bapak, karib-kerabat, anak-anak yatim, orang-orang miskin, tetangga yang dekat, tetangga yang jauh, teman sejawat, ibnu sabil, dan hamba sahayamu. Sesungguhnya Allah tidak menyukai orang-orang yang sombong dan membanggakan diri (Q.S. An-Nisa: 36).

Penjelasan ayat di atas dapat disimpulkan bahwa akhlak dibagi dua macam yaitu, pertama, akhlak kepada Allah meliputi: beribadah (Ibadah), berzikir (zikr), berdo'a, bertaqwa (tawakkal), berserah diri (thawadu') kepada Allah SWT. Kedua, akhlak kepada manusia dibagi menjadi dua yaitu perilaku terpuji (mahmudah) dan perilaku tercela (mazmumah) (Zulkifli, 2018). Misalnya perilaku terpuji, yaitu suka membantu kepada orang lain (ta'awun), berbaik sangka (husnuzhan), rendah hati (thawadu'), dan saling menghormati dan menghargai kepada sesama (tasamuh). Perilaku tercela yaitu tidak senang atau cemburu kepada orang lain yang beruntung (hasad), dendam, dan membicarakan kejelekan orang lain untuk menjatuhkannya (ghibah dan fitnah), dan adu domba (namimah) (Zulkifli, 2018).

Istilah akhlak seringkali disandingkan kepada karakter (Amin, 2016), akan tetapi pada hakikatnya kedua hal itu berbeda. Karakter merupakan sekumpulan tata nilai yang menuju pada suatu sistem yang melandasi pemikiran, sikap dan perilaku yang ditampilkan (Muin, 2011). Karakter dibagi menjadi dua bagian yaitu, pertama, orang yang menunjukkan perilaku tidak jujur, kejam, atau rakus, tentulah orang tersebut memanifestasikan perilaku yang buruk (tercela), sebaliknya orang yang menunjukkan 
perilaku jujur, suka menolong, tentulah orang itu memanifestasikan perilaku mulia (terpuji). Kedua karakter erat kaitannya dengan kepribadian (personality). Orang bisa disebut dengan orang yang berkarakter apabila tingkah lakunya sesuai dengan kaidahkaidah moral (Muin, 2011).

Akhlak berasal dari bahasa Arab yaitu "khalqun" jamak dari kata "khuluqu" artinya sebagai "budi pekerti, perangai, tingkah laku, atau tabiat" (Zulkifli, 2018), dan akhlak juga memiliki kedekatan dengan istilah tata krama atau sopan santun (Adisusilo, 2013). Imam Al-Ghazali mengatakan bahwa akhlak memiliki 4 komponen, yaitu: Pertama, perbuatan yang baik dan buruk; Kedua, kemampuannya dalam melakukan perbuatan itu; Ketiga, kesadaran akan perbuatan yang dilakukannya; dan Keempat, kondisi jiwa yang condong kepada salah satu yang akan membuatnya mudah untuk mengerjakan salah satu dari dua perkara baik dan buruk (Al-Ghazali, 2014).

Jhon B Watson mengatakan bahwa perilaku manusia merupakan hasil dari bawaan (genetis) dan pengaruh lingkungan atau situasional (Nahar, 2016). Perubahan perilaku disebabkan adanya stimulus yang diberikan lingkungan sehingga stimulus tersebut akan menimbulkan sebuah respon dari stimulus. Teori behavioristik juga menekankan pada perubahan tingkah laku sebagai akibat dari interaksi antara stimulus dan respons (Familus, 2016). Perilaku dimaknai oleh teori behaviorisme sesuai dengan kata behavior itu, yaitu tingkah laku yang dilakukan baik oleh organisme, sistem, atau entitas buatan dalam suatu hubungan dengan lingkungan mereka yang meliputi sistem lain atau organisme sekitar (Zulhammi, 2015). Akan tetapi, dalam teori behavioristik hanya bisa melihat perubahan perilaku manusia dengan hal-hal yang tampak dan dapat dianalisis.

Paparan di atas menunjukkan adanya indegius dalam perubahan perilaku. Adanya kesamaan pada pemikiran dua tokoh dalam mengubah perilaku yaitu Imam AlGhazali dan Ivan Pavlov yang mengatakan dengan pembiasaan akan dapat merubah perilaku manusia dari buruk menjadi baik dan akan menjadi sebuah hebitz dalam diri manusia tersebut. Inilah yang menjadi poin penting (starting point) dan yang menarik peneliti ingin melakukan sebuah penelitian terhadap pemikiran kedua tokoh tersebut.

Kajian ini memfokuskan masalah yang bertitik tolak pada: 1) Bagaimana konsep pembiasaan Imam Al-Ghazali dapat mengubah perilaku manusia?, 2) Bagaimana konsep pembiasaan Ivan Pavlov dapat mengubah perilaku manusia? 3) Bagaimana model kajian pembiasan dalam membentuk perilaku peserta didik perspektif Imam AlGhazali dan Ivan Pavlov?

Tujuan penelitian ini untuk mendeskripsikan konsep pembiasaan dalam upaya membentuk perilaku peserta didik menurut perspektif Imam Al-Ghazali dan Ivan Pavlov. Asumsi yang terdapat dalam penelitian ini yaitu adanya keterkaitan antara kedua konsep atau teori tersebut yang mengatakan bahwa akhlak merupakan refleksi dari pembiasaan-pembiasaan yang dilakukan dengan latihan yang terus menerus sehingga menjadi sebuah tabiat pada dirinya. 


\section{B. METODE}

Penelitian kualitatif kepustakaan (library research) merupakan jenis penelitian ini, yaitu sebuah penelitian yang mengumpulkan seluruh data dan informasi yang terdapat dalam kepustakaan atau buku (Herdiansyah, 2015). Paradigma penelitian ini menggunakan teori perilaku yang mengarahkan cara berpikir (Kasiram, 2010), dalam memaparkan pembiasaan Imam al-Ghazali dan Pavlov.

Pendekatan penelitian menggunakan historis-filosofis untuk mendapatkan data tentang pemikiran Imam Al-Ghazali dan Ivan Pavlov dan content analysis bertujuan untuk menganalisis, menelaah, dan mendeskripsikan data yang dihasilkan dalam pemikiran Imam Al-Ghazali dan Ivan Pavlov. Sumber penelitian terdiri dari sumber primer dan sekunder (Rizal, 2018). Sumber primer berupa buku-buku atau karya-karya Imam Al-Ghazali yaitu Ihya al-Ulumuddin, Metode Menaklukkan Jiwa: Pengendalian Nafsu Dalam Perspektif Sufistik dan buku-buku psikologi yang membahas pemikiran Ivan Pavlov. Sedangkan sumber data sekunder yang diambil adalah semua data yang mendukung dan berkaitan dengan penelitian ini dan yang dapat menjelaskan pemikiran kedua tokoh tersebut.

\section{PEMIKIRAN IMAM AL-GHAZALI}

Imam Al-Ghazali memiliki nama lengkap Abu Hamid Muhammad bin Muhammad bin Muhammad bin Ahmad Al-Ghazali, yang dikenal sebagai Hujjatul Islam Zainuddin AlThusi. Ia lahir pada tahun 450 H/1058 M di kota Thusia yaitu wilayah dari Khurazan (Persia) (Al-Ghazali, 1998). Ayahnya seorang pedagang pakaian yang terbuat dari wol di pasar Thusia dan merupakan tokoh sufistik. Ketika ayahnya meninggal pada waktu ia masih kecil meninggalkan sebuah pesan kepada temannya yang seorang ahli tasawuf agar mendidik Al-Ghazali dan adiknya bernama Ahmad (Al-Ghazali, 2011).

Al-Ghazali pertama kali belajar ilmu Fiqh di kota Thus kepada Ahmad bin Muhammad al-Radzkani pada tahun 465 H/ 1073 M, setelah selesai kemudian melanjutkan pendidikan ke kota Jurjan dan berguru kepada Syekh Abul Qasim bin Ismail bin Masadat al-Jurjani yang ber-Mazhab Syafi'i (Al-Ghazali, 2011). Kemudian pada tahun $473 \mathrm{H} / 1086 \mathrm{M}$, beliau melanjutkan pendidikan ke Naishabur untuk belajar berbagai bidang ilmu pengetahuan yaitu fiqh, mantiq, filsafat dan ilmu al-ushul (teologi) kepada Imam Al-Haramain Abul Malalii Abdul Malik al-Juwaini (Al-Ghazali, 2011).

Setelah menyelesaikan pendidikan, Imam Al-Ghazali berangkat ke Nizamul-muluk. Kemudian wazir Nizamul-muluk menaruh simpati kepadanya dan mengangkat AlGhazali menjadi guru besar di Perguruan Tinggi Nizamiyah pada tahun $484 \mathrm{H}$ yang didirikan di kota Bagdad (Al-Ghazali, 2011). Setelah empat tahun lamanya Al-Ghazali melakukan aktivitas mengajar, beliau mulai ditimpa dengan berbagai kesulitan berupa goncangan batin. Inilah fase kedua Imam Al-Ghazali yaitu masa syakk (ragu) terhadap kebenaran ilmu yang didapatnya dan terhadap yang dipegangnya. Sehingga pada fase ini dia lebih banyak menghabiskan waktunya untuk melakukan perjalanan (Al-Ghazali, 1998). 
Pemikiran Imam Al-Ghazali mengatakan bahwa manusia memang sangat dikuasai oleh rasa malas sehingga menumbuhkan rasa enggan untuk melakukan atau menempuh jalan spritualitas (mujahadah) pendisiplinan diri, menyucikan jiwa, dan mendidik perilaku. Hal ini disebabkan karena dua alasan yang melatarbelakangi pemikiran manusia, yaitu pertama, seseorang beranggapan bahwa perilaku (khuluq) adalah sifat bawaan sejak lahir (innate respons) yang menurutnya tidak akan dapat diubah lagi (AlGhazali, 2014). Misalnya orang yang kurus tidak akan pernah menjadi ngemuk, dan orang jelek tidak akan pernah menjadi tampan. Kedua, seseorang beranggapan bahwa mengubah perilaku berarti harus menghancurkan amarah dan hawa nafsu yang ada dalam diri, sehingga akan berusaha terus-menerus untuk menghilangkan hal itu dalam kehidupannya. Sedangkan pada hakikatnya kedua ini tidak akan pernah lepas dalam kehidupan manusia, disebabkan sudah menjadi watak dan sifat dari seseorang (AlGhazali, 2014).

Untuk menanggapi kedua pendapat di atas, seandainya perilaku tidak bisa diubah maka tidak ada gunanya segala nasihat, ceramah, khutbah dan berbagai pendisiplinan lainnya. Nabi Saw juga bersabda, "perbaikilah akhlakmu". Hadis ini menjelaskan bahwa setiap perilaku yang ada dalam diri manusia itu bisa diubah. Sebagaimana kita berpandangan terhadap benda-benda di alam semesta ini yang dibagi dua macam, yaitu pertama, benda yang bersifat independen yang tidak memerlukan campur tangan dan ikhtiar dari manusia, seperti matahari, bintang dan lainnya. Kedua, benda yang bersifat dependen (tidak sempurna) yang membutuhkan campur tangan dan ikhtiar manusia, misalnya hawa nafsu dan amarah.

Proses mengubah perilaku dalam diri manusia itu bervariasi. Ada yang cepat (instan) dan ada yang lama (berperiode) dalam mengubahnya. Hal ini terjadi disebabkan dua alasan yaitu, pertama, adanya insting (gharizah) yang akan mempermudah untuk menumbuhkan perilaku dalam diri manusia seiring pertumbuhan dari usia. Oleh karena itu, seseorang yang dapat menggunakan pikiran atau insting dengan baik tidak mudah terpengaruh oleh hal-hal yang merugikan dirinya. Kedua, untuk mengubah perilaku membutuhkan pembiasaan yang kuat (alta'awuudu alqawiu) yang dapat memberikan keyakinan terhadap sesuatu yang baik itu akan memberikan kepuasan kepada dirinya (Al-Ghazali, 2014). Dengan tujuan mengembalikan keseimbangan yang berada pada titik tengah antara hal-hal yang berlebihan dan kekurangan.

Dalam proses pembiasaan ini, Imam Al-Ghazali membagi manusia dalam empat tipe yaitu pertama, orang dungu yang tidak dapat membedakan antara yang baik dan buruk, atau antara yang benar dan salah. Orang semacam ini hanya membutuhkan pembimbing yang dapat mengantarkan perilaku yang baik dalam dirinya. Kedua, orang yang telah mengenal kualitas buruk dari perbuatan yang buruk dan belum terbiasa mengerjakan perbuatan yang baik. Manusia dalam tipe ini masih bisa diberikan pembiasaan atau pendisiplinan jika memang bersedia dan bersungguh-sungguh dalam melaksanakannya. Ketiga, orang yang memiliki keyakinan bahwa perilaku buruklah yang diwajibkan dan dianggap paling benar. Pembiasaan pada tipe semacam ini nyaris 
mustahil, disebabkan harapan yang sangat kecil untuk diperbaiki. Keempat, orang yang tumbuh dengan keyakinan yang rusak dan dididik untuk mengerjakannya sehingga beranggapan bahwa kebaikan merupakan kejahatan dan kekejian. Pembiasaan pada tipe semacam ini sulit untuk dilakukan dan kemungkinan besar tidak bisa dilakukan (ALGhazali).

\section{PEMIKIRAN IVAN PETROVICH PAVLOV}

Ivan Petrovich Pavlov lahir pada tanggal 14 September tahun 1849 di Ryazan Rusia yaitu tempat ayahnya Pater Dmitrievich Pavlov menjadi seorang pendeta (Sugihartono dkk, 2013). Ia dididik di sekolah gereja dan melanjutkan ke seminari. Pavlov lulus sebagai sarjana kedokteran dengan bidang dasar fisiologi. Pada tahun 1884 ia menjadi Direktur Departemen Fisiologi pada Institute of Experimental Medicine dan memulai penelitian mengenai fisiologi pencernaan. Ivan Pavlov meraih penghargaan Nobel dalam bidang Phisiology and Medicine pada tahun 1904. Karyanya mengenai pengondisian yaitu Word of Digestive Glands (1902) dan conditioned reflexes (1927), sangat mempengaruhi psikologi behavioristik di Amerika (Sugihartono dkk, 2013).

Pavlov mengatakan bahwa perilaku dapat berubah dengan adanya proses pembiasaan yang ditandai dengan interaksi antara stimulus dan respon (Rohmah, 2012). Hal itu dijelaskan berdasarkan temuannya mengenai pengondisian klasik (classical conditioning) yaitu suatu percobaan melalui anjing yang diberikan stimulus bersyarat yaitu perangsang asli dan netral. Perangsang ini dilakukan secara berulang-ulang sehingga memunculkan reaksi yang diinginkan respons. Penelitiannya mengenai pengondisian klasik ini dapat dilihat berikut:

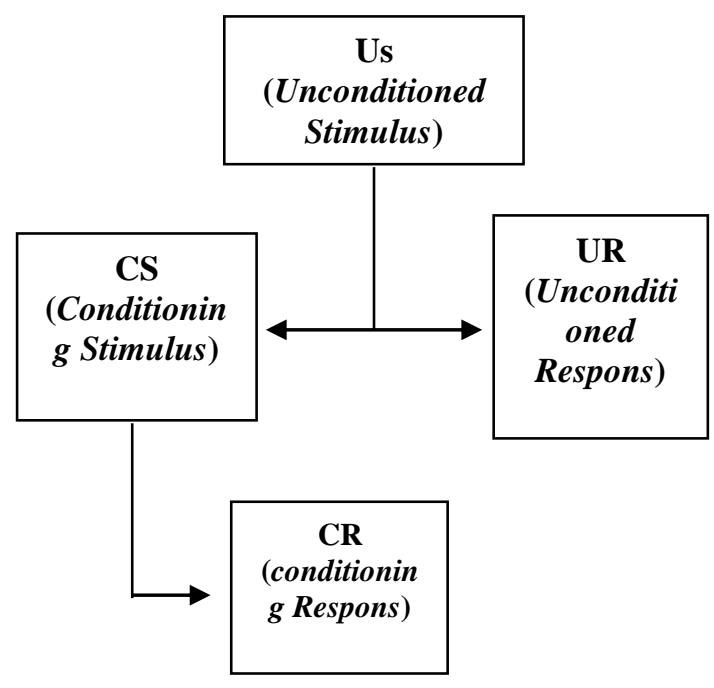

Gambar.1

Proses Terjadinya Classical Conditioning

Dalam eksperimen Pavlov ini, bisa dilihat penjelasan berikut ini: 
- US (Unconditioned Stimulus): Sebuah stimulus asli atau netral yang dipergunakan untuk menimbulkan respon secara langsung, misalnya daging dapat merangsang anjing untuk mengeluarkan air liur.

- UR (Unconditioned Respons): Sebuah respons yang tak bersyarat, maksudnya timbulnya sebuah respons disebabkan hadirnya sebuah stimulus netral US, misalnya air liur anjing keluar karena ada daging.

- CS (Conditioning Stimulus): stimulus bersyarat, yaitu stimulus yang tidak dapat langsung menimbulkan respon, oleh karena itu untuk dapat menimbulkan respon perlu digunakan dengan US secara terus menerus. Misalnya: bunyi bel akan mengeluarkan air liur jika selalu dipasangkan dengan daging.

- CR (Conditioning Respons): respons bersyarat, yaitu respon yang muncul disebabkan hadirnya CS. Misalnya, air liur anjing keluar karena anjing mendengar bel.

Dari eksperimen Pavlov menyatakan bahwa setelah melakukan pengkondisi atau pembiasaan dapat diketahui bahwa daging yang menjadi stimulus alami dapat digantikan oleh bunyi bel atau lonceng sebagai stimulus yang dikondisikan. Dan ketika lonceng tersebut dibunyikan ternyata air liur anjing keluar inilah yang disebutnya respon yang dikondisikan (conditoning respons) (Sugihartono dkk, 2013). Secara harfiah, eksperimen Pavlov ini tunduk pada dua macam hukum yaitu, law of respondent conditioning, berarti suatu hukum pembiasaan yang dituntut, dan law of respondent extinction berarti suatu hukum pemusnahan yang dituntut (Muhibbin Syah, 2003).

Law of respondent conditioning yang dimaksud ketika memberikan dua macam stimulus secara simultan, dan salah satu dari stimulus tersebut berfungsi sebagai reinforcer, akan menghasilkan sebuah respons yang dikondisikan (respondent conditioning). Sedangkan law of respondent extinctioni adalah ketika menghadirkan respondent conditioning kembali tanpa adanya penguatan dengan reinforcer maka kekuatan dari refleks akan menurun (Muhibbin Syah, 2003).

Dalam pandangan Ivan Pavlov mengatakan bahwa aktivitas-aktivitas manusia dibagi kepada dua dimensi yaitu, Pertama, aktivitas yang bersifat reflektif, berupa respon yang timbul tanpa menyadari kehadiran dari suatu stimulus tertentu (unconcinius state), Kedua, aktivitas yang disadari (concinius state), berupa respon yang timbul sebab adanya reaksi dari stimulus yang diberikan secara terus-menerus terhadap objek tertentu (Purwanto, 2014). Dengan demikian, proses interaksi antara stimulus dan respons pada tahap kesadaran ini lebih panjang, dibandingkan respons pada tahap refleksif atau keadaan tidak sadar (LN \& Juntika, 2007).

Peran dari clasical conditioning dalam membentuk kepribadian individu adalah untuk memberikan kontribusi terhadap pembentukan respon-respon secara emosional, seperti rasa cemas, takut atau phobia. Walaupun kontribusi tersebut sangat kecil kemungkinan, namun dalam pembentukan reaksi-reaksi secara emosional yang maladaptif sangat diperlukan (LN \& Juntika, 2007). Misalnya, peserta didik yang mengalami rasa cemas terhadap pembelajaran, disebabkan sering mendapat teguran, kritikan, atau peringatan yang negatif dari guru dalam setiap proses pembelajaran. 
Dengan demikian, teguran yang bersifat negatif dari guru merupakan (US) yang dipasangkan dalam proses belajar (CS) akan menimbulkan sebuah kecemasan (CR). Hal ini dapat disimpulkan bahwa kecemasan tetap ada dalam diri peserta didik meskipun guru sedang tidak berada dalam proses pembelajaran tersebut. Proses tersebut dapat digambarkan seperti berikut.

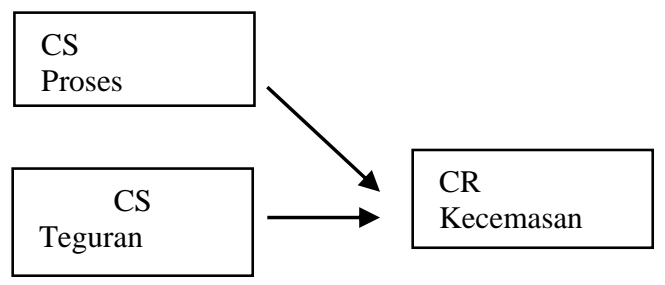

Gambar .2

Proses terjadinya kecemasan (UR)

\section{E. METODE MENDIDIK KARAKTER}

Karakter yang baik merupakan buah dari keseimbangan daya rasional dari sifat amarah (ghadab) dan hawa nafsu (syahwat) (Al-Ghazali, 1995). Untuk mencapai pada keseimbangan, maka bisa dilakukan dengan dua cara: Pertama dengan rahmat Allah dan kesempurnaan sifat bawaan (kamal fithri), yakni individu yang dilahirkan dengan mempunyai daya rasional lebih tinggi akan lebih mudah untuk menyeimbangkan sifat amarah dan hawa nafsu. Kedua pendisiplinan dengan melalui perjuangan batiniah untuk memperoleh sifat-sifat yang baik dalam dirinya. Pendisiplinan merupakan suatu proses membiasakan diri dalam mengerjakan perbuatan yang sesuai dengan perilaku yang ingin dicapai (Al-Ghazali, 2014). Misalnya, individu yang ingin memiliki sifat pemurah, harus membiasakan aktivitas kehidupannya dengan sifat-sifat pemurah seperti dermawan atau bersedekah, dengan menjalankan proses ini terus-menerus dan bersungguh-sungguh akan menjadi hebits yang hai'ah dalam dirinya.

Untuk memanifestasikan kondisi di atas dalam kepribadian individu, maka harus melalui beberapa tahapan sebagai berikut: Pertama, Takhalli yang merupakan langkah pertama yang harus dijalani oleh seseorang, yaitu usaha mengosongkan diri dari perilaku tercela (Naution \& Siregar, 2007). Pencapaian pada tahapan ini dilakukan dengan menjauhkan diri dari segala perbuatan maksiat dan berusaha mengendalikan hawa nafsu. Maka diperlukan keadaan jiwa yang sehat untuk membuka jalan keluar dan kemuliaan dari dalam hati (qalbu), sebaliknya jiwa rusak pasti akan menimbulkan kekacauan walaupun dilindungi oleh sebuah sistem yang baik. Setiap individu yang memiliki kerusakan dalam jiwanya dengan berbagai cara tetap akan melaksanakan keinginan-keinginan yang rendah atau buruk (Al-Ghazali, 1995).

Pembersihan jiwa pada tahapan takhalli ini merupakan sebuah US (unconditioning stimulus) dalam Teori Pavlov. Ia mengatakan bahwa dengan memberikan stimulus netral akan bisa menimbulkan respon secara langsung yang 
disebut dengan reflex wajar (unconditioned reflex) (Purwanto, 2014). Keadaan jiwa yang bersih akan memanifestasikan perbuatan-perbuatan yang mulia atau perilaku yang terpuji (unconditioning respons). Maka dalam hal ini, penentuan atau pemilihan stimulus netral yang dapat menimbulkan sebuah respons yang tak bersyarat sangat diperlukan. Misalkan, seseorang yang belajar akan menjadi pandai, proses belajar adalah US dan pandai adalah UR.

Kedua, Tahalli merupakan upaya mengisi atau menghiasi diri dengan jalan membiasakan diri dengan sikap dan perilaku baik (Nasution \& Siregar, 2007). Tahapan tahalli dilakukan untuk mendorong proses pada tahapan takhalli dalam pembersihan jiwa dalam merefleksikan perilaku-perilaku baik. Pada tahapan ini merupakan sebuah proses pembiasaan dalam melakukan aktivitas-aktivitas yang mencerminkan perilaku baik atau menghiasi diri dengan suatu perbuatan yang dapat diajarkan oleh agama dan akhlak yang mulia (Zulkifli, 2018). Dalam diri manusia pada prinsipnya terdapat fitrah yang baik dan selalu menginginkan kebaikan serta merasa bahagia bila dapat mengerjakannya (Al-Ghazali, 1995).

Pavlov mengatakan bahwa ketika ingin mengubah perilaku, maka harus memberikan terlebih dahulu sebuah stimulus syarat conditioning stimulus dengan cara membiasakan secara terus-menerus, sehingga akan memanifestasikan refleks bersyarat (unconditioning refleks)

(Purwanto, 2014). Misalnya, seseorang yang membaca buku dengan sungguh-sungguh akan menjadi pandai, membaca buku dengan sungguh-sungguh adalah CS atau tahalli dan pandai adalah UR. Pengondisian stimulus merupakan sebuah kebiasaan yang harus dilakukan kepada responden agar memunculkan perilaku yang diinginkan.

Ketiga, Tajalli yaitu pemantapan dan pendalaman dari kedua fase/tahapan sebelumnya yaitu takhalli dan tahalli. Rangkaian pembentukan perilaku baik disempurnakan pada tahapan ini. Tahap tajalli ini termasuk penyempurnaan kesucian jiwa yang hanya dapat ditempuh dengan jalan cinta kepada Allah dan memperdalam rasa kecintaan itu dengan membiasakan perilaku terpuji dalam kehidupan sehari-hari (Nasution \& Siregar, 2007). Menurut Imam Al-Ghazali, perilaku baik akan timbul disebabkan karena kesucian jiwa yang sudah kita didik dan kita bimbing dengan suatu proses latihan mujahadah (Al-Ghazali, 2008).

Perubahan akhlak atau perilaku seseorang sehingga menjadi sebuah habits yang hai'ah dalam diri dapat dilakukan dengan menggabungkan antara takhalli (unconditioning stimulus) dan tahalli (conditioning stimulus) yang dilakukan secara terus-menerus akan menimbulkan respons atau refleks bersyarat (conditioning respons). Misalnya orang yang belajar dan membaca buku dengan sungguh-sungguh akan manjadikannya pandai dan berwawasan luas.

Perilaku bukan sesuatu yang hanya dipelajari dalam ruang lingkup pendidikan saja, akan tetapi perilaku juga dapat direalisasikan ke dalam kepribadian seseorang sehingga memanifestasikan akhlakul karimah (Amin, 2016). Salah satu metode atau cara yang dapat membentuk perilaku manusia adalah dengan proses pembiasaan terhadap perilaku baik secara terus-menerus dalam aktivitas kehidupan. Pembiasaan 
merupakan sesuatu cara yang perlu ditanamkan dalam membentuk pribadi yang berakhlak (Amin, 2016). Misalnya, membiasakan diri untuk berkata lembut kepada orang lain, kelak pembiasaan ini akan menjadi hebitz dalam pribadi seseorang.

\section{F. SIMPULAN}

Kesimpulan dalam penelitian ini adalah untuk dapat mengubah suatu perilaku atau akhlak dalam diri manusia bisa dilakukan dengan menempuh jalan pembiasaan yang secara terus menerus diimplementasikan. Sebagaimana yang dikatakan oleh Imam AlGhazali dan Ivan Pavlov, melalui proses pembiasaan yang dilakukan oleh individu akan dapat mengubah perilaku buruk menjadi perilaku baik yang akan menjadi habits dalam dirinya. Proses tersebut akan menimbulkan perilaku yang baik secara simultan (hai'ah) tanpa memerlukan sebuah pertimbangan dan pemikiran. Hal itu dapat dilalui dengan tiga tahapan yaitu takhalli (unconditioning stimulus), tahalli (conditioning stimulus), dan tajalli yang akan menimbulkan conditioning respon.

\section{DAFTAR PUSTAKA}

Adisusilo, S. (2013). Pembelajaran Nilai-Karakter Konstruktivisme dan VCT Sebagai Pendekatan Pembelajaran Afektif. Jakarta: Raja Grafindo Persada.

Ahmad, M. 2011. Agama dan Psikoanalisa Sigmund Freud. Religia Jurnal Ilmu-ilmu. Keislaman. 14(2), 277-296. doi: https://doi.org/10.28918/religia.v14i2.92

Al-Ghazali, I.M. 1995. Khuluqul Muslim, Terj. Bandung: Al-Ma'arif. 1998. al-Munqidz min Adh-Dhala, Terj. Bandung: Pustaka Hidayah 2008. Mukhtasyar Ihya' 'Ulumuddin, Terj. Yogyakarta: Absolut. 2011. Ihya' 'Ulumiddin, Terj. Jakarta: Republika Penerbit

2014. Metode Menaklukkan Jiwa: Pengendalian Nafsu Dalam Perspektif Sufistik, Terj. Bandung: MizanPustaka.

Amin, M. S. 2016. Ilmu Akhlak. Jakarta: Amzah.

Nasution, B. A. \& Siregar, H. R. 2007. Akhlak Tasawuf. Depok: Raja Grafindo Persada.

Custers, Ruud \&Aarts, A. 2010. The Unconscious Will: How the Pursuit of Goals Operates Outside of Conscious Awareness. Science. 329 (5987), 47-50. DOI: 10.1126/science. 1188595

Familus. 2016. Teori Belajar Aliran Behavioristik Serta Implikasinya dalam Pembelajaran Improvisasi Jazz. Jurnal PPKn \& Hukum. https://doi.org/10.1007/s00267-011-9698-0

Herdiansyah, H. 2015. Metodologi Penelitian Kualitatif Untuk Ilmu Psikologi. Jakarta: Salemba Humanika.

Kasiram, H. M. 2010. Metodologi Penelitian. Malang: UIN-Maliki Press.

Mz, R. S. 2018. Akhlak Islami Perspektif Ulama Salaf. Edukasi Islami: Jurnal Pendidikan Islam. https://doi.org/10.30868/ei.v7i01.212

Muin, F. 2011. Pendidikan Karakter Konstruksi Teori \& Praktek. Jakarta: Ar-Ruzz Media. 
LN, Y. S., \& Juntika, A. N. (2007). Teori Kepribadian. Bandung: Remaja Rosdakarya. Nahar, I. N. 2016. Penerapan Teori Belajar Behavioristik Dalam Proses Pembelajaran. Jurnal Ilmu Pengetahuan Sosial. https://doi.org/10.1111/j.13652141.1992.tb08137.x

Purwanto, N. M. 2014. Psikologi Pendidikan. Bandung: Remaja Rosdakarya.

Rohmah, Noer. 2012. Psikologi Pendidikan. Yogyakarta: Penerbit Teras.

Sugihartono, Agus. F. S, Rohmah. S. N., \& Kartika. N. 2013. Psikologi Pendidikan. Yogyakarta: UNY Press

Syah, M. 2003. Psikologi Belajar. Jakarta: Raja Grafindo Persada

Zahruddin, \& Hasanuddin. 2004. Pengantar Studi Akhlak. Jakarta: Raja Grafindo Persada.

Zulfahmi, S., \& Hasmah, W. M. 2014. Perbandingan Pemikiran Konsep Akhlak AlGhazali Dan Ibn Miskawayh Dalam Aspek Intelek. The Online Journal of Islamic Education, 2, (2), 107-119.

Zulhammi. 2015. Teori Belajar Behavioristik dan Humanistik Dalam Perspektif Pendidikan Islam. Jurnal Darul Ilmi. 3(1). 105-127.

Zulkifli. 2018. Akhlak Tasawuf Jalan Lurus Mensucikan Diri. Yogyakarta: Kalimedia. 